\title{
Poster
}

\section{Preliminary comparative RH mapping between river buffalo chromosome 6 (BBU6) and bovine chromosome 3 (BTA3)}

\author{
N. Bonvino Stafuzza1 ${ }^{1}$ P. Ianella ${ }^{1}$, M. Nunes Miziara ${ }^{1}$, \\ R. Agarwala², A.A. Schäffer², P. K. Riggs ${ }^{3}$, \\ J.E. Womack ${ }^{4}$, M.E.J. Amaral ${ }^{1}$ \\ 1UNESP - São Paulo State University, IBILCE, Dept. Biologia, São Jose Rio Preto, Brazil \\ ${ }^{2}$ National Center for Biotechnology Information, National Institutes of Health, Department of \\ Health and Human Services, Bethesda, Maryland, USA \\ ${ }^{3}$ Department of Animal Science, Texas A\&M University, College Station, TX, USA \\ ${ }^{4}$ Department of Veterinary Pathobiology, Texas A\&M University, College Station, USA
}

Corresponding author: M.E.J. Amaral, Universidade Estadual Paulista (UNESP-São José do Rio Preto, São Paulo, Brazil). E-mail: eamaral@ibilce.unesp.br

\begin{abstract}
We present the first radiation hybrid map of BBU6 developed from a recently constructed river buffalo whole-genome radiation hybrid panel $\left(\mathrm{BBURH}_{5000}\right)$. The preliminary map contains 33 cattle-derived markers, including 12 microsatellites, 19 coding genes and two ESTs, distributed in two linkage groups. The retention frequency of individual markers ranged from $14.4 \%$ to $40.0 \%$. Most of the marker order within the linkage groups is consistent with the cattle sequence and $\mathrm{RH}$ maps. This preliminary BBU6 $\mathrm{RH}$ map is the starting point for comparing gene order between both species, presenting an opportunity for examination of micro-rearrangements of these chromosomes and, thereby enhancing the possibility of positional candidate cloning in river buffalo.
\end{abstract}


